\title{
Correction to: QTL Detection for Flowering-Time Related Traits in Miscanthus sinensis Using a Staggered-Start Design
}

Wei Hou ${ }^{1} \cdot$ Raphaël Raverdy $^{1} \cdot$ Kristelle Lourgant $^{1} \cdot$ Emilie Mignot $^{2} \cdot$ Stéphanie Arnoult $^{2} \cdot$ Catherine Giauffret $^{1}$. Maryse Brancourt-Hulmel ${ }^{1}$ (D)

Published online: 3 March 2022

○) Springer Science+Business Media, LLC, part of Springer Nature 2022

\section{Correction to: BioEnergy Research}

https://doi.org/10.1007/s12155-021-10386-x

\begin{abstract}
In the text below Model 3, it should be written $\left(\alpha^{\prime} \gamma\right)_{\mathrm{ik}}$ instead of $\left(\alpha^{\prime} \gamma\right)_{\text {ikil }}$.

In the text below Model 3, it should be written $\left(\alpha^{\prime} \gamma\right)_{\text {ik }}$ instead of $\left(\alpha^{\prime} \gamma\right)_{\text {ikil. }}$
\end{abstract}

The original version has been corrected.

Publisher's Note Springer Nature remains neutral with regard to jurisdictional claims in published maps and institutional affiliations.

The original article can be found online at https://doi.org/10.1007/ s12155-021-10386-x.

Maryse Brancourt-Hulmel maryse.hulmel@inrae.fr

1 BioEcoAgro Joint Research Unit, INRAE AgroImpact, University of Liege, University of Lille, University of Picardie Jules Verne, Site of Estrees-Mons, 5013680203 Peronne Cedex, CS, France

2 UE GCIE Picardie, INRAE, Estrees-Mons, 80203 Peronne, France 